\title{
Genetics of Multiple Sclerosis: An Overview and New Directions
}

\author{
Nikolaos A. Patsopoulos ${ }^{1,2}$ \\ ${ }^{1}$ Department of Neurology, Brigham \& Women's Hospital and Harvard Medical School, Boston, \\ Massachusetts 02115 \\ ${ }^{2}$ Program in Medical and Population Genetics, Broad Institute, Cambridge, Massachusetts 02142 \\ Correspondence: npatsopoulos@rics.bwh.harvard.edu
}

\begin{abstract}
The contribution of genetic inheritance in multiple sclerosis was established early on. Although multiple sclerosis is not a Mendelian disease, its incidence and prevalence is higher in family members of affected individuals compared with the general population. Throughout the last decade, several small studies failed to identify any robust genetic associations besides the classic associations in the major histocompatibility complex region. During the past few years, genome-wide association studies (GWAS) have revolutionized the genetics of multiple sclerosis, uncovering more than 200 implicated genetic loci. Here, we describe these main findings and discuss the new avenues that these discoveries lay open.
\end{abstract}

\begin{abstract}
ultiple sclerosis (MS) is an inflammatory disease of the central nervous system (CNS), resulting in progressive neurodegeneration and neurological disability (Bansil et al. 1995). MS most commonly affects young adults, especially women. From the early characterization years of the disease, it was apparent that there are both genetic and environmental influences (Sadovnick et al. 1997; Sawcer et al. 2014). For more than 30 years, studies on genetics of MS have unraveled a significant piece of the puzzle that is MS. Genetic studies provide an important piece toward understanding the yet elusive etiology of this complex disease.
\end{abstract}

\section{MULTIPLE SCLEROSIS'S HERITABILITY}

The role of genetic contribution to MS emerged from both twin and familial clustering studies
(Sawcer et al. 2014). Monozygotic or identical twins were shown to exhibit significantly higher clinical concordance rate $(25 \%-30 \%)$ than dizygotic or fraternal twins $(3 \%-7 \%)$, a difference that potentially contributes to the low penetrance of this disease (Dyment et al. 1997), that is, the low likelihood that any particular genotype will manifest in MS. Family history of MS has been reported in $15 \%-20 \%$ of MS patients, much higher than the prevalence in the general population (Compston and Coles 2002). The lifetime risk of MS in first-degree relatives of MS index cases is estimated at 3\% ( $4 \%$ for siblings, $2 \%$ for parents, $2 \%$ for children), or threefold greater than the age-adjusted risk for second-degree and third-degree relatives (1\%) and 10 - to 30 -fold greater than the ageadjusted risk in the general population $(0.1 \%-$ 0.3\%) (Compston and Coles 2002; Sawcer et al.

Editors: Howard L. Weiner and Vijay K. Kuchroo

Additional Perspectives on Multiple Sclerosis available at www.perspectivesinmedicine.org

Copyright (C 2018 Cold Spring Harbor Laboratory Press; all rights reserved; doi: 10.1101/cshperspect.a028951

Cite this article as Cold Spring Harb Perspect Med 2018;8:a028951 
N.A. Patsopoulos

2014). The risk of MS is markedly higher if both parents have MS and the risk of half-siblings is lower than that of full siblings, whereas the risk for step-siblings of MS index cases and for individuals adopted by families with MS are similar to the general population. Thus, the familial recurrence risk of MS increases in proportion to the amount of genetic sharing with the affected family member but not in a linear relationship. A meta-analysis of more than 500 studies reported a recurrence risk for monozygotic twins of $18.2 \%$ and $2.7 \%$ for siblings, and a sibling relative risk ( $\lambda \mathrm{s}$ ) of 16.8 (O'Gorman et al. 2013). More recently, studies on large national registries allowed more accurate heritability estimates in MS. An Italian large-scale study of up to 50 million individuals ascertained 216 twin pairs and calculate a heritability estimate of 0.48 (95\% confidence interval [CI], $0.06-0.86$ ), whereas the environmental contribution was 0.29 (95\% CI, 0-0.60) for shared and 0.23 (95\% CI, 0.12-0.39) for unique (individualspecific) environmental factors (Ristori et al. 2006). A national registry study of $\sim 15$ million individuals in Sweden reported 28,396 registered patients with MS (Westerlind et al. $2014 b)$. The investigators estimated a sibling recurrence risk ( $\lambda s=7.1 ; 95 \% \mathrm{CI}, 6.42-7.86)$ and they reported a heritability estimate of 0.64 (95\% CI, 0.28-0.77) based on 348 proband twins with MS. This estimate was refined further by adding information on siblings and half-siblings to 0.64 (95\% CI, 0.36-0.76). Interestingly, they could not find any shared environmental component (0.01 with $05 \%$ CI, 0-0.18; the individual-specific environmental component was 0.35 with 95\% CI, 0.24-0.51). Despite the national level of these studies and their large sample size, it is obvious that studies of heritability based on twin studies are not free of methodological limitations, whereas wide CIs imply luck of ability to refine heritability estimated even at the national level (Hawkes and Macgregor 2009; Fagnani et al. 2014; Westerlind et al. 2014a).

\section{CANDIDATE GENE ASSOCIATIONS}

The strong evidence of heritable component in MS from the early population studies motivated the identification of the genetic culprits. This first era of genetic association studies was plagued by many small studies that were underpowered to identify any true associations. The MSgene database has a historical archive of $>700$ genetic studies in MS (see msgene.org). Despite the wide lack of corroboration in genetic studies of MS, there were few true associations that were uncovered. The human leukocyte antigen (HLA) gene cluster on chromosome 6p21 had been mostly consistently identified as the strongest genetic locus for MS from candidate gene association studies and genome-linkage approaches using microsatellite markers (Hollenbach and Oksenberg 2015). HLA genes encode polymorphic cell surface glycoproteins that are involved in immune regulation via recognition of either intracellular nonself (class I) or extracellular proteins (class II) (Shiina et al. 2009). The HLA genes reside within the highly polymorphic major histocompatibility complex (MHC) region that has been associated with MS susceptibility for some time. This signal was initially described as being part of the HLA class I genes (Bertrams et al. 1972; Naito et al. 1972; Jersild et al. 1973; Winchester et al. 1975); however, it was later refined to the class II region (HLA-DR2) (Compston et al. 1976; Haines et al. 1998). Further developments in molecular techniques allowed the localization of the HLA-DR2 locus to two separate molecular allotypes, HLA-DR* 15 and HLA-DR* 16 , whereas the MS signal was further refined to HLA-DRB1*15 (Olerup and Hillert 1991; Barcellos et al. 2002) and later on to HLADRB1 $^{*}$ 15:01 (Barcellos et al. 2002; Hollenbach and Oksenberg 2015).

\section{GENOME-WIDE STUDIES AND IDENTIFICATION OF COMMON VARIANTS}

The striking absence of replicated genetic associations (Ioannidis et al. 2001), despite the overwhelming number of studies, highlighted a fundamental problem of the genetic model assumed in genetics of common diseases. The scientific community was extremely successful in identifying the causal variants of several rare diseases by leveraging familial designs. This suc- 
cess was never evident in common diseases, even when larger scale linkage studies were performed. In MS, linkage studies failed to identify any genetic associations (Ebers et al. 1996; Modin et al. 2003; Haghighi et al. 2006; Willer et al. 2007; Dyment et al. 2008). It became evident that common diseases with a heritable component have different genetic architecture compared with Mendelian diseases. The theory of common disease-common variant (CDCV) was proposed to address these issues (Reich and Lander 2001). CDCV states that common diseases in a population are caused by several small common genetic variations, that is, with high allele frequency in the population. In the case of MS, this implies that there could be hundreds of common variants that each of them will have a small effect toward causing the disease. The evidence accumulated from familial studies via segregation analysis also suggested that MS has one locus with moderate effect (HLA$\left.\mathrm{DRB}^{*} 15: 01\right)$ and many loci with small effects (O’Gorman et al. 2013).

To accommodate the study of the CDCV hypothesis, several technological advancements had to converge to allow for the agnostic investigation of the whole genome. Chip arrays were developed that could simultaneously genotype hundreds of thousands genetic positions, whereas hypercomputing systems provided the necessary computing power to run millions of associations. Genome-wide association studies (GWAS) were introduced in the mid-2000s, and this new study design enabled the hypothesis-free interrogation of the genome. Two main aspects of GWAS studies were challenging. The investigation of hundreds of thousands of genetic variants would lead to an increase rate of false positive results while using the nominal level of statistical significance $(p$-value $<0.05)$. Thus, the concept of genome-wide levels of significance was introduced, with a $p$-value of $5 \times 10^{-8}$ being the most widely used threshold. Finally, the requirement for large samples to increase the power to identify small effects necessitated a culture of collaboration in the scientific community.

The first GWAS in MS subjects was published in 2007 and was performed by the International Multiple Sclerosis Genetics Con- sortium (IMSGC), using 931 family trios and a replication cohort of 2322 MS subjects and 2987 controls (International Multiple Sclerosis Genetics Consortium et al. 2007). This first GWAS identified the first-ever genome-wide association in MS, outside the MHC region, rs12722489, which lies in the first intron of IL2RA (odds ratio $[\mathrm{OR}]=1.25, p$-value $=$ $\left.2.96 \times 10^{-8}\right)$. The IL2RA gene encodes the $\alpha$ chain of the interleukin- 2 receptor, which plays a role in several immune-related pathways (Liao et al. 2011). Interestingly, IL2RA is the target of the MS-approved drug daclizumab (Bielekova et al. 2004). In the following years, several more GWAS and follow-up studies increased the number of genome-wide associated MS variants to more than 40 (Wellcome Trust Case Control Consortium et al. 2007; Aulchenko et al. 2008; Comabella et al. 2008; Australia and New Zealand Multiple Sclerosis Genetics 2009; Baranzini et al. 2009; De Jager et al. 2009c; Jakkula et al. 2010; Nischwitz et al. 2010; Sanna et al. 2010; International Multiple Sclerosis Genetics Consortium et al. 2011, 2013b; Patsopoulos et al. 2011; Martinelli-Boneschi et al. 2012; Matesanz et al. 2012; Andlauer et al. 2016). In parallel with advancements in the MS-genetics, many genome-wide variants were discovered in several other autoimmune diseases (Stahl et al. 2010; Trynka et al. 2011; Jostins et al. 2012). A striking realization was that several of these were common across several autoimmune diseases. For example, the TAGAP gene locus has been associated with MS susceptibility; the same direction of effect is present in type I diabetes and rheumatoid arthritis, and the opposite effect occurs in celiac disease (Patsopoulos et al. 2011). This pleiotropic nature of genetic variants was leveraged in designing the ImmunoChip (IC), an array that aimed to fine-map 186 genomic regions associated with at least one autoimmune disease (Parkes et al. 2013). The IC enabled a low-cost interrogation of several autoimmune diseases at a large scale (Trynka et al. 2011; Eyre et al. 2012; Jostins et al. 2012; Liu et al. 2012, 2013; Mayes et al. 2014). In MS, the IC study analyzed 14,498 subjects with MS and 24,091 healthy controls to identify 110 genome-wide variants 
N.A. Patsopoulos

(International Multiple Sclerosis Genetics Consortium et al. 2013a).

Several of the largest studies were meta-analyses of case control studies that were genotyped with different arrays (De Jager et al. 2009c; Patsopoulos et al. 2011). These meta-analyses of GWAS were facilitated by advancements in the fields of population and statistical genetics that enabled the completion of the haplotypic structure of reference populations (International HapMap Consortium 2005) and the parallel development of statistical algorithms and programs that could leverage these references to impute single nucleotide polymorphisms (SNPs) in GWASs (Marchini and Howie 2010).

In a similar fashion, the complex structure of the HLA genes was captured by creating reference panels, including SNPs, HLA alleles, and corresponding amino acids (Jia et al. 2013). These HLA-specific reference panels, coupled with advanced imputation algorithms, allowed the in-depth investigation of the $\mathrm{MHC}$ region in MS (Patsopoulos et al. 2013). The refinement of the HLA-DRB1*15:01-HLA-DQA1*06:02 was possible, proving that HLA-DRB1*15:01 is the driving allele in these European ancestry populations. HLA-DRB1 was proven to have multiple independent associations with MS $\left({ }^{*} 03: 01\right.$, ${ }^{*} 13: 03,{ }^{*} 04: 04,{ }^{*} 04: 01$, and $\left.{ }^{*} 14: 01\right)$, with four amino-acid changes (positions 71, 74, 57, and 86), capturing most of them (Patsopoulos et al. 2013). All of these amino-acid positions reside in the peptide-binding groove of the HLA-DR molecule, thus affecting binding and recognition of antigens. The nature of HLA associations in MS is even more complex with interacting HLA alleles. Small studies suggested the presence of HLA interactions (Lincoln et al. 2009) and larger genetic studies have verified their existence at genome-wide levels (Moutsianas et al. 2015). The role of these interactions is rather elusive; however, it seems to be a more extensive mechanism since interactions with $\mathrm{MHC}$ with non-MHC regions have been reported (Galarza-Munoz et al. 2017).

Currently, the largest genetic study in MS has analyzed 47,351 cases and 68,284 healthy controls, and has identified 233 genome-wide loci associated with MS susceptibility (Patso- poulos and International Multiple Sclerosis Genetics Consortium 2016). Two hundred of these loci reside in the autosomal non-MHC genome, and explain $\sim 20 \%$ of the MS genetics. The effect size of these loci is relatively small, ranging from ORs of 1.05 to 1.2 , as expected according to the CVCD hypothesis. This study has also identified the first-ever chromosome X variant in MS. The associated variant, rs2807267, is within an enhancer peak area specific for $\mathrm{T}$ cells and resides downstream from the RNA U6 small nuclear 320 pseudogene (RNU6-320P). RNU6$320 \mathrm{P}$ is a component of the U6 small nuclear ribonucleoprotein ( $\mathrm{snRNP}$ ), which is part of the spliceosome and is responsible for the splicing of introns from pre-messenger RNA (premRNA) (Fortner et al. 1994). This finding opens up a new era of exploring the role of sex chromosomes in MS.

The discovery of genetic associations with disease susceptibility is not the desired end goal in MS genetics. The identification of the causal genes and their functional consequences is necessary to uncover affected mechanisms and pathways. Unfortunately, several limitations have not allowed the same rate of progress in causal gene mapping as the discovery of the genetic culprits. The vast majority of MS-associated variants fall within either intronic or intragenic regions (Patsopoulos and International Multiple Sclerosis Genetics Consortium 2016). Just recently, we have started to understand that this part of the genome is involved in regulatory mechanisms (Encode Project Consortium 2012; Roadmap Epigenomics Consortium et al. 2015). Several of the MS risk variants are within regions that are promoters or enhancers of nearby genes (Maurano et al. 2012). The few successful functional studies following GWAS findings have suggested that the identified genetic variants could alter splicing of exons that lead to different isoforms. More specifically, GWAS variants lead to alternate splicing of IL7R, IL2R, and TNFRSF1A, creating soluble forms of these genes that could inhibit downstream signaling (Gregory et al. 2007, 2012; Maier et al. 2009). Other variants could change the expression of nearby genes (De Jager et al. 2009a; Raj et al. 2014). Functional studies of MS variants still 
have a way to go; however, advances in RNA-seq and other high-throughput technologies are paving the way toward the creation of MS-specific genomic maps. These genomic maps can allow the parallel functional characterization of MS variants in a cell-specific and environmentaware way.

Despite the lack of functional characterization of the hundreds MS risk variants and their small effect sizes, we can gain invaluable knowledge by studying them together. Enrichment methods that take into account all the identified variants can prioritize the affected tissues and cells ( $\mathrm{Hu}$ et al. 2011; Maurano et al. 2012; Slowikowski et al. 2014; Pers et al. 2015). These methods leverage extensive expression, or other -omic maps and allow the relative ranking of affected cells or tissues. In MS, enrichment methods strongly implicate several different immune system cells, for example, regulatory $\mathrm{T}$ cells and B cells, whereas CNS tissues have no sign of being implicated (Patsopoulos and International Multiple Sclerosis Genetics Consortium 2016). A possible explanation is that the majority of the genetic MS variants alter regulation of immune-related genes. Furthermore, the lack of enrichment in brain tissues does not exclude the possibility that a handful of these genetic variants could directly affect neuronal tissue or supporting cell types. What we can state with certainty is that the ensemble of the MS-associated variants acts via immune system cells and related mechanisms. This is on par with GWAS discoveries in other autoimmune diseases that affect systems other than the CNS (Hu et al. 2011; Farh et al. 2015). Pathway analyses of the GWAS variants also point to the same realization (International Multiple Sclerosis Genetics Consortium et al. 2011, 2013a). Immune system-related and signaling pathways are strongly implicated, as well as T- and B-cell differentiation and cross-immune cell communication pathways (Patsopoulos and International Multiple Sclerosis Genetics Consortium 2016).

\section{RARE VARIANTS}

The success of GWAS to identify common variants led to the discovery of low-frequency variants. An open question is whether there are monogenic forms of the disease that are caused by rare variants that have a very strong effect. One study performed exome sequencing in MS subjects from 43 families with four or more affected individuals, and reported a rare variant in the CYP27B1 gene that caused complete loss of gene function in one individual (Ramagopalan et al. 2011). A large-scale replication study (Ban et al. 2013) and a targeted sequencing study (Barizzone et al. 2013) both failed to replicate this finding. Another study based on familial data suggested that the mutation p.Arg415Gln in NR1H3 causes a severe and progressive Mendelian form of the disease (Wang et al. 2016). No corroboration was feasible in a study of 32,852 MS cases and 36,538 controls (International Multiple Sclerosis Genetics Consortium 2016). Additionally, an investigation using the Exome Aggregation Consortium (ExAC) reported several individuals carrying this mutation with no reported MS or related disease (Minikel and MacArthur 2016). To date, there is no evidence of monogenic forms of MS; however, detailed investigations using whole-genome sequencing methods have not yet been performed. Any associations with rare variation in MS are yet to be proven.

\section{SUBPHENOTYPES AND POPULATION HETEROGENEITY}

Although the discovery of MS susceptibility loci has been very successful, with more than 200 genome-wide so far, this success has not been translated into subphenotypes of the disease. No association was identified with primary progressive MS or the MS Severity Score (MSSS) in any of the published studies (Jensen et al. 2010; International Multiple Sclerosis Genetics Consortium 2011; George et al. 2016), whereas some reports exist for magnetic resonance imaging (MRI) measurements that need further replication to be considered robust (Gourraud et al. 2013; Matsushita et al. 2015). On the contrary, studies on laboratory measurements have been successful. A study has identified a genome-wide association for the extent of intrathecal immunoglobulin G (IgG) in MS (Buck 
N.A. Patsopoulos

et al. 2013). The associated variants were located in the immunoglobulin heavy chain (IGHC) locus on chromosome $14 \mathrm{q} 32.33$, which was also implicated by an independent study (DelgadoGarcia et al. 2015). Furthermore, a third study identified two novel associations within the MHC region and IgG index (Goris et al. 2015).

The majority of GWAS in any disease or trait are performed on European ancestry populations. Evidence from other diseases suggests that genetic susceptibility could be different in diverse populations. In MS, for example, it is established that HLA associations on the island of Sardinia are different that the ones from mainland Italy (Marrosu et al. 1998). Unfortunately, GWAS on non-European populations in MS have not been performed on the same scale as those done on European ancestry populations. Genetic studies in African-American MS subjects have so far uncovered a shared genetic background with the European populations (Johnson et al. 2010; Isobe et al. 2013, 2015), although the studied sample size has yet to reach the point where distinct genetic associations can be uncovered. A small study in MS subjects from India also suggested shared genetic risk with European populations (Pandit et al. 2011), whereas a study in Ashkenazi Jews pointed toward HLA-A*68:02 and HLA-B*38:01-HLA$C^{*}$ 12:03 haplotypes (Khankhanian et al. 2015).

\section{CROSS-DISEASE ASSOCIATIONS}

MS has increased comorbidity with other inflammatory diseases (Nielsen et al. 2008), with a common denominator of the attack of tissues by the immune system. It is well established that family members of individuals with MS are at increased risk for other autoimmune diseases and there is mounting evidence for a shared genetic background (Cotsapas et al. 2011). Several genes implicated in autoimmune diseases are pleiotropic, that is, are associated with more than one disease (Wagner and Zhang 2011). About a third of the MS-associated genetic variants have been reported at genome-wide levels in at least one other autoimmune disease (Patsopoulos et al. 2011). Empirical proof of the existence of extended genetic background across autoimmune diseases has been the success of the IC studies. The low cost of this autoimmunetargeted array allowed the genotyping and analysis of almost 10-fold more samples than traditional GWAS arrays, thus enabling early discovery of many genetic variants in MS and other diseases.

The genetic overlap of autoimmune diseases concurs with the role of the immune system deregulation, and an important question is whether genetics can explain the involvement of the CNS in MS. Few studies comparing MS with other neurological diseases have been performed. A comparison with amyotrophic lateral sclerosis found no shared association (Goris et al. 2014), neither did a study contrasting schizophrenia (Andreassen et al. 2015). A larger effort comparing 23 diseases affecting the brain, including MS, found evidence of overlap between other neurological diseases but not MS (Anttila et al. 2016).

\section{GENETIC RISK SCORE TO PREDICT DISEASE SUSCEPTIBILITY}

The polygenic architecture of MS with hundreds of causal genetic variants with small effects implied that no single variant could be used to predict disease susceptibility. The concept of aggregated risk score was introduced to take into account the complex genetic predisposition (Wray et al. 2007). Several disease associated genetic variants can be aggregated into a genetic risk score (GRS), in an unweighted or weighted fashion. Unweighted GRS is a simple summation of the copies of risk alleles in one's genome. Weighted GRS (wGRS) adjusts the risk alleles by multiplying with the effect size of each variant. One of the first wGRS studies in MS incorporated $19 \mathrm{MS}$ risk loci and had an area-under-thecurve (AUC) of 0.70 to predict MS status in an independent case-control data set (De Jager et al. 2009b). The AUC could be improved by adding gender information to 0.74 ; however, the wGRS could not predict conversion of a clinically isolated syndrome to MS. Another implementation of wGRS in 1213 independent MS families (810 sporadic and 403 multicase families found a higher correlation in multicase fam- 
ilies compared with sporadic (Gourraud et al 2011). This study also failed to observe any ability of the wGRS to predict case-control status. A study using a wGRS of 110 variants in 842 Belgian MS patients and 321 controls observed a correlation even in extremes subphenotypes, for example, oligoclonal band-negative and primary progressive MS (Hilven et al. 2015). Moreover, they reported an association between high non-HLA wGRS and increased relapse rate and shorter relapse-free intervals after disease onset.

Several other studies identified associations between wGRS and subphenotypes and clinical course (Harbo et al. 2014; Pan et al. 2016), thus suggesting that the clinical utility of GRS might increase as more detailed clinical information is incorporated.

\section{ENVIRONMENT AND GENETICS}

MS has a strong environmental component. Several factors have been implicated with few having high levels of corroborating evidence. An interesting question is whether environment and genetics interact to cause MS. Unfortunately, the study of environment and common diseases is plagued by many problems, such as selection bias, confounding, and reverse causation. Mendelian randomization (MR) has been proposed to overcome these issues and provide a robust framework to resolve environmental exposure (Smith and Ebrahim 2003). MR is derived from Mendel's law of independent assortment (Monaghan and Corcos 1984), which states that the inheritance of genetic variants is independent. MR in a way is similar to an intention-to-treat analysis in randomized clinical trials (RCTs) (Davey Smith and Ebrahim 2005). The genetic "exposure" is randomly assigned to be present in one group and absent in the other, as does the intervention in RCTs. Thus, an unbiased estimate of the effect of the genetic exposure's effect on the final outcome can be derived (Davey Smith and Ebrahim 2005). MR has just recently started to get traction in MS genetics. A study of 25-hydroxyvitamin $\mathrm{D}(25 \mathrm{OHD})$ reported a twofold increase in the odds of MS (Mokry et al. 2015) that was corroborated by another independent MR study (Rhead et al. 2016). Finally, another MR study suggested that increased body mass index (BMI) influences MS susceptibility and 1 standard deviation increase in BMI $\left(\mathrm{kg} / \mathrm{m}^{2}\right)$ is associated with an OR of 1.41 (95\% CI, 1.20-1.66) to be susceptible to MS.

\section{CONCLUDING REMARKS}

Genetics of MS have come a long way in the last few years. Hundreds of susceptibility loci have been identified, which can explain about half of the disease's heritability. Progress in secondary phenotypes has not been on par so far, but deep phenotyping efforts and context-aware analyses are encouraging for many important discoveries to come. New methods to explore the functional implications of the identified genetic variants and their interaction with environmental changes will lead to a new chapter of MS genetics.

\section{ACKNOWLEDGMENTS}

N.A.P. thanks the many multiple sclerosis individuals who provided their genetic and other data to the scientific community. N.A.P. thanks the research community of the Ann Romney Center of Neurological Diseases at the Brigham \& Women's Hospital, and the many collaborators at the International Multiple Sclerosis Genetics Consortium. N.A.P. has received support from the National Multiple Sclerosis Society throughout his career in genetics of multiple sclerosis and is an Erase MS Young Investigator.

\section{REFERENCES}

Andlauer TF, Buck D, Antony G, Bayas A, Bechmann L, Berthele A, Chan A, Gasperi C, Gold R, Graetz C, et al. 2016. Novel multiple sclerosis susceptibility loci implicated in epigenetic regulation. Sci Adv 2: e1501678.

Andreassen OA, Harbo HF, Wang Y, Thompson WK, Schork AJ, Mattingsdal M, Zuber V, Bettella F, Ripke S, Kelsoe JR, et al. 2015. Genetic pleiotropy between multiple sclerosis and schizophrenia but not bipolar disorder: Differential involvement of immune-related gene loci. Mol Psychiatry 20: 207-214.

Anttila V, Bulik-Sullivan B, Finucane HK, Bras J, Duncan L, Escott-Price V, Falcone G, Gormley P, Malik R, Pat- 
N.A. Patsopoulos

sopoulos N, et al. 2016. Analysis of shared heritability in common disorders of the brain. bioRxiv doi: 10.1101/ 048991.

Aulchenko YS, Hoppenbrouwers IA, Ramagopalan SV, Broer L, Jafari N, Hillert J, Link J, Lundstrom W, Greiner E, Dessa Sadovnick A, et al. 2008. Genetic variation in the KIF1B locus influences susceptibility to multiple sclerosis. Nat Genet 40: 1402-1403.

Australia and New Zealand Multiple Sclerosis Genetics Consortium. 2009. Genome-wide association study identifies new multiple sclerosis susceptibility loci on chromosomes 12 and 20. Nat Genet 41: 824-828.

Ban M, Caillier S, Mero IL, Myhr KM, Celius EG, Aarseth J, Torkildsen O, Harbo HF, Oksenberg J, Hauser SL, et al. 2013. No evidence of association between mutant alleles of the CYP27B1 gene and multiple sclerosis. Ann Neurol 73: 430-432.

Bansil S, Cook SD, Rohowsky-Kochan C. 1995. Multiple sclerosis: Immune mechanism and update on current therapies. Ann Neurol 37: S87-S101.

Baranzini SE, Wang J, Gibson RA, Galwey N, Naegelin Y, Barkhof F, Radue EW, Lindberg RL, Uitdehaag BM, Johnson MR, et al. 2009. Genome-wide association analysis of susceptibility and clinical phenotype in multiple sclerosis. Hum Mol Genet 18: 767-778.

Barcellos LF, Oksenberg JR, Green AJ, Bucher P, Rimmler JB, Schmidt S, Garcia ME, Lincoln RR, Pericak-Vance MA Haines JL, et al. 2002. Genetic basis for clinical expression in multiple sclerosis. Brain 125: 150-158.

Barizzone N, Pauwels I, Luciano B, Franckaert D, Guerin FR, Cosemans L, Hilven K, Salviati A, Dooley J, DansoAbeam D, et al. 2013. No evidence for a role of rare CYP27B1 functional variations in multiple sclerosis. Ann Neurol 73: 433-437.

Bertrams J, Kuwert E, Liedtke U. 1972. HL-A antigens and multiple sclerosis. Tissue Antigens 2: 405-408.

Bielekova B, Richert N, Howard T, Blevins G, MarkovicPlese S, McCartin J, Frank JA, Wurfel J, Ohayon J, Waldmann TA, et al. 2004. Humanized anti-CD25 (daclizumab) inhibits disease activity in multiple sclerosis patients failing to respond to interferon $\beta$. Proc Natl Acad Sci 101: 8705-8708.

Buck D, Albrecht E, Aslam M, Goris A, Hauenstein N, Jochim A; International Multiple Sclerosis Genetics C, Wellcome Trust Case Control Consortium; Cepok S, Grummel V, et al. 2013. Genetic variants in the immunoglobulin heavy chain locus are associated with the IgG index in multiple sclerosis. Ann Neurol 73: 86-94.

Comabella M, Craig DW, Camina-Tato M, Morcillo C, Lopez C, Navarro A, Rio J, Biomarker MSSG, Montalban X, Martin R. 2008. Identification of a novel risk locus for multiple sclerosis at $13 \mathrm{q} 31.3$ by a pooled genome-wide scan of 500,000 single nucleotide polymorphisms. PLoS ONE 3: e3490.

Compston A, Coles A. 2002. Multiple sclerosis. Lancet 359: 1221-1231.

Compston DA, Batchelor JR, McDonald WI. 1976. B-lymphocyte alloantigens associated with multiple sclerosis. Lancet 2: 1261-1265.

Cotsapas C, Voight BF, Rossin E, Lage K, Neale BM, Wallace C, Abecasis GR, Barrett JC, Behrens T, Cho J, et al. 2011.
Pervasive sharing of genetic effects in autoimmune disease. PLoS Genet 7: e1002254.

Davey Smith G, Ebrahim S. 2005. What can Mendelian randomisation tell us about modifiable behavioural and environmental exposures? BMJ 330: 1076-1079.

De Jager PL, Baecher-Allan C, Maier LM, Arthur AT, Ottoboni L, Barcellos L, McCauley JL, Sawcer S, Goris A, Saarela J, et al. 2009a. The role of the CD58 locus in multiple sclerosis. Proc Natl Acad Sci 106: 5264-5269.

De Jager PL, Chibnik LB, Cui J, Reischl J, Lehr S, Simon KC Aubin C, Bauer D, Heubach JF, Sandbrink R, et al. 2009b. Integration of genetic risk factors into a clinical algorithm for multiple sclerosis susceptibility: A weighted genetic risk score. Lancet Neurol 8: 1111-1119.

De Jager PL, Jia X, Wang J, de Bakker PI, Ottoboni L, Aggarwal NT, Piccio L, Raychaudhuri S, Tran D, Aubin C, et al. 2009c. Meta-analysis of genome scans and replication identify CD6, IRF8 and TNFRSF1A as new multiple sclerosis susceptibility loci. Nat Genet 41: 776-782.

Delgado-Garcia M, Matesanz F, Alcina A, Fedetz M, GarciaSanchez MI, Ruiz-Pena JL, Fernandez O, Pinto Medel MJ, Leyva L, Arnal C, et al. 2015. A new risk variant for multiple sclerosis at the immunoglobulin heavy chain locus associates with intrathecal IgG, IgM index and oligoclonal bands. Mult Scler 21: 1104-1111.

Dyment DA, Sadovnick AD, Ebers GC. 1997. Genetics of multiple sclerosis. Hum Mol Genet 6: 1693-1698.

Dyment DA, Cader MZ, Herrera BM, Ramagopalan SV, Orton SM, Chao M, Willer CJ, Sadovnick AD, Risch N, Ebers GC. 2008. A genome scan in a single pedigree with a high prevalence of multiple sclerosis. J Neurol Neurosurg Psychiatry 79: 158-162.

Ebers GC, Kukay K, Bulman DE, Sadovnick AD, Rice G, Anderson C, Armstrong H, Cousin K, Bell RB, Hader W, et al. 1996. A full genome search in multiple sclerosis. Nat Genet 13: 472-476.

Encode Project Consortium. 2012. An integrated encyclopedia of DNA elements in the human genome. Nature 489: $57-74$.

Eyre S, Bowes J, Diogo D, Lee A, Barton A, Martin P, Zhernakova A, Stahl E, Viatte S, McAllister K, et al. 2012 High-density genetic mapping identifies new susceptibility loci for rheumatoid arthritis. Nat Genet 44: 13361340.

Fagnani C, Ricigliano VA, Buscarinu MC, Nistico L, Salvetti M, Stazi MA, Ristori G. 2014. Shared environmental effects on multiple sclerosis susceptibility: Conflicting evidence from twin studies. Brain 137: e287.

Farh KK, Marson A, Zhu J, Kleinewietfeld M, Housley WJ, Beik S, Shoresh N, Whitton H, Ryan RJ, Shishkin AA, et al. 2015. Genetic and epigenetic fine mapping of causal autoimmune disease variants. Nature 518: 337-343.

Fortner DM, Troy RG, Brow DA. 1994. A stem/loop in U6 RNA defines a conformational switch required for premRNA splicing. Genes Dev 8: 221-233.

Galarza-Munoz G, Briggs FB, Evsyukova I, Schott-Lerner G Kennedy EM, Nyanhete T, Wang L, Bergamaschi L, Widen SG, Tomaras GD, et al. 2017. Human epistatic interaction controls IL7R splicing and increases multiple sclerosis risk. Cell 169: 72-84.e13. 
George MF, Briggs FB, Shao X, Gianfrancesco MA, Kockum I Harbo HF, Celius EG, Bos SD, Hedstrom A, Shen L, et al. 2016. Multiple sclerosis risk loci and disease severity in 7,125 individuals from 10 studies. Neurol Genet 2: e87.

Goris A, van Setten J, Diekstra F, Ripke S, Patsopoulos NA, Sawcer SJ; International Multiple Sclerosis Genetics Consortium; van Es M; Australia and New Zealand MS Genetics Consortium, et al. 2014. No evidence for shared genetic basis of common variants in multiple sclerosis and amyotrophic lateral sclerosis. Hum Mol Genet 23: 1916-1922.

Goris A, Pauwels I, Gustavsen MW, van Son B, Hilven K, Bos SD, Celius EG, Berg-Hansen P, Aarseth J, Myhr KM, et al. 2015. Genetic variants are major determinants of CSF antibody levels in multiple sclerosis. Brain 138: 632-643.

Gourraud PA, McElroy JP, Caillier SJ, Johnson BA, Santaniello A, Hauser SL, Oksenberg JR. 2011. Aggregation of multiple sclerosis genetic risk variants in multiple and single case families. Ann Neurol 69: 65-74.

Gourraud PA, Sdika M, Khankhanian P, Henry RG, Beheshtian A, Matthews PM, Hauser SL, Oksenberg JR, Pelletier D, Baranzini SE. 2013. A genome-wide association study of brain lesion distribution in multiple sclerosis. Brain 136: $1012-1024$.

Gregory SG, Schmidt S, Seth P, Oksenberg JR, Hart J, Prokop A, Caillier SJ, Ban M, Goris A, Barcellos LF, et al. 2007. Interleukin 7 receptor $\alpha$ chain (IL7R) shows allelic and functional association with multiple sclerosis. Nat Genet 39: 1083-1091.

Gregory AP, Dendrou CA, Attfield KE, Haghikia A, Xifara DK, Butter F, Poschmann G, Kaur G, Lambert L, Leach OA, et al. 2012. TNF receptor 1 genetic risk mirrors outcome of anti-TNF therapy in multiple sclerosis. Nature 488: $508-511$.

Haghighi S, Andersen O, Nilsson S, Rydberg L, Wahlstrom J. 2006. A linkage study in two families with multiple sclerosis and healthy members with oligoclonal CSF immunopathy. Mult Scler 12: 723-730.

Haines JL, Terwedow HA, Burgess K, Pericak-Vance MA, Rimmler JB, Martin ER, Oksenberg JR, Lincoln R, Zhang DY, Banatao DR, et al. 1998. Linkage of the MHC to familial multiple sclerosis suggests genetic heterogeneity. The Multiple Sclerosis Genetics Group. Hum Mol Genet 7: 1229-1234.

Harbo HF, Isobe N, Berg-Hansen P, Bos SD, Caillier SJ, Gustavsen MW, Mero IL, Celius EG, Hauser SL, Oksenberg JR, et al. 2014. Oligoclonal bands and age at onset correlate with genetic risk score in multiple sclerosis. Mult Scler 20: 660-668.

Hawkes CH, Macgregor AJ. 2009. Twin studies and the heritability of MS: A conclusion. Mult Scler 15: 661-667.

Hilven K, Patsopoulos NA, Dubois B, Goris A. 2015. Burden of risk variants correlates with phenotype of multiple sclerosis. Mult Scler 21: 1670-1680.

Hollenbach JA, Oksenberg JR. 2015. The immunogenetics of multiple sclerosis: A comprehensive review. J Autoimmun 64: 13-25.

Hu X, Kim H, Stahl E, Plenge R, Daly M, Raychaudhuri S 2011. Integrating autoimmune risk loci with gene-expression data identifies specific pathogenic immune cell subsets. Am J Hum Genet 89: 496-506.
International HapMap Consortium. 2005. A haplotype map of the human genome. Nature 437: 1299-1320.

International Multiple Sclerosis Genetics Consortium. 2011. Genome-wide association study of severity in multiple sclerosis. Genes Immun 12: 615-625.

International Multiple Sclerosis Genetics Consortium. 2016. $\mathrm{NR} 1 \mathrm{H} 3$ p.Arg415Gln is not associated to multiple sclerosis risk. Neuron 92: 333-335.

International Multiple Sclerosis Genetics Consortium; Hafler DA, Compston A, Sawcer S, Lander ES, Daly MJ, De Jager PL, de Bakker PI, Gabriel SB, Mirel DB, et al. 2007. Risk alleles for multiple sclerosis identified by a genomewide study. N Engl J Med 357: 851-862.

International Multiple Sclerosis Genetics Consortium; Wellcome Trust Case Control Consortium 2; Sawcer S Hellenthal G, Pirinen M, Spencer CC, Patsopoulos NA, Moutsianas L, Dilthey A, Su Z, et al. 2011. Genetic risk and a primary role for cell-mediated immune mechanisms in multiple sclerosis. Nature 476: 214-219.

International Multiple Sclerosis Genetics Consortium; Beecham AH, Patsopoulos NA, Xifara DK, Davis MF, Kemppinen A, Cotsapas C, Shah TS, Spencer C, Booth D, et al. 2013a. Analysis of immune-related loci identifies 48 new susceptibility variants for multiple sclerosis. Nat Genet 45: 1353-1360.

International Multiple Sclerosis Genetics Consortium; Lill CM, Schjeide BM, Graetz C, Ban M, Alcina A, Ortiz MA, Perez J, Damotte V, Booth D, et al. 2013b. MANBA, CXCR5, SOX8, RPS6KB1 and ZBTB46 are genetic risk loci for multiple sclerosis. Brain 136: 1778-1782.

Ioannidis JP, Ntzani EE, Trikalinos TA, Contopoulos-Ioannidis DG. 2001. Replication validity of genetic association studies. Nat Genet 29: 306-309.

Isobe N, Gourraud PA, Harbo HF, Caillier SJ, Santaniello A, Khankhanian P, Maiers M, Spellman S, Cereb N, Yang S, et al. 2013. Genetic risk variants in African Americans with multiple sclerosis. Neurology 81: 219-227.

Isobe N, Madireddy L, Khankhanian P, Matsushita T, Caillier SJ, More JM, Gourraud PA, McCauley JL, Beecham AH, International Multiple Sclerosis Genetics C, et al. 2015. An ImmunoChip study of multiple sclerosis risk in African Americans. Brain 138: 1518-1530.

Jakkula E, Leppa V, Sulonen AM, Varilo T, Kallio S, Kemppinen A, Purcell S, Koivisto K, Tienari P, Sumelahti ML, et al. 2010. Genome-wide association study in a high-risk isolate for multiple sclerosis reveals associated variants in STAT3 gene. Am J Hum Genet 86: 285-291.

Jensen CJ, Stankovich J, Van der Walt A, Bahlo M, Taylor BV, van der Mei IA, Foote SJ, Kilpatrick TJ, Johnson LJ, Wilkins E, et al. 2010. Multiple sclerosis susceptibilityassociated SNPs do not influence disease severity measures in a cohort of Australian MS patients. PLoS ONE 5: e10003.

Jersild C, Fog T, Hansen GS, Thomsen M, Svejgaard A, Dupont B. 1973. Histocompatibility determinants in multiple sclerosis, with special reference to clinical course. Lancet 2: 1221-1225.

Jia X, Han B, Onengut-Gumuscu S, Chen WM, Concannon PJ, Rich SS, Raychaudhuri S, de Bakker PI. 2013. Imputing amino acid polymorphisms in human leukocyte antigens. PLoS ONE 8: e64683. 
N.A. Patsopoulos

Johnson BA, Wang J, Taylor EM, Caillier SJ, Herbert J, Khan OA, Cross AH, De Jager PL, Gourraud PA, Cree BC, et al. 2010. Multiple sclerosis susceptibility alleles in African Americans. Genes Immun 11: 343-350.

Jostins L, Ripke S, Weersma RK, Duerr RH, McGovern DP, Hui KY, Lee JC, Schumm LP, Sharma Y, Anderson CA, et al. 2012. Host-microbe interactions have shaped the genetic architecture of inflammatory bowel disease. Nature 491: 119-124.

Khankhanian P, Matsushita T, Madireddy L, Lizee A, Din L, More JM, Gourraud PA, Hauser SL, Baranzini SE, Oksenberg JR. 2015. Genetic contribution to multiple sclerosis risk among Ashkenazi Jews. BMC Med Genet 16: 55.

Liao W, Lin JX, Leonard WJ. 2011. IL-2 family cytokines: New insights into the complex roles of IL-2 as a broad regulator of $\mathrm{T}$ helper cell differentiation. Curr Opin Immunol 23: 598-604.

Lincoln MR, Ramagopalan SV, Chao MJ, Herrera BM, Deluca GC, Orton SM, Dyment DA, Sadovnick AD, Ebers GC. 2009. Epistasis among HLA-DRB1, HLA-DQA1, and $H L A-D Q B 1$ loci determines multiple sclerosis susceptibility. Proc Natl Acad Sci 106: 7542-7547.

Liu JZ, Almarri MA, Gaffney DJ, Mells GF, Jostins L, Cordell HJ, Ducker SJ, Day DB, Heneghan MA, Neuberger JM, et al. 2012. Dense fine-mapping study identifies new susceptibility loci for primary biliary cirrhosis. Nat Genet 44: 11371141.

Liu JZ, Hov JR, Folseraas T, Ellinghaus E, Rushbrook SM, Doncheva NT, Andreassen OA, Weersma RK, Weismuller TJ, Eksteen B, et al. 2013. Dense genotyping of immune-related disease regions identifies nine new risk loci for primary sclerosing cholangitis. Nat Genet 45: 670-675.

Maier LM, Anderson DE, Severson CA, Baecher-Allan C, Healy B, Liu DV, Wittrup KD, De Jager PL, Hafler DA. 2009. Soluble IL-2RA levels in multiple sclerosis subjects and the effect of soluble IL-2RA on immune responses. J Immunol 182: 1541-1547.

Marchini J, Howie B. 2010. Genotype imputation for genomewide association studies. Nat Rev Genet 11: 499-511.

Marrosu MG, Murru MR, Costa G, Murru R, Muntoni F, Cucca F. 1998. DRB1-DQA1-DQB1 loci and multiple sclerosis predisposition in the Sardinian population. Hum Mol Genet 7: 1235-1237.

Martinelli-Boneschi F, Esposito F, Brambilla P, Lindstrom E, Lavorgna G, Stankovich J, Rodegher M, Capra R, Ghezzi A, Coniglio G, et al. 2012. A genome-wide association study in progressive multiple sclerosis. Mult Scler 18: 1384-1394.

Matesanz F, Gonzalez-Perez A, Lucas M, Sanna S, Gayan J, Urcelay E, Zara I, Pitzalis M, Cavanillas ML, Arroyo R, et al. 2012. Genome-wide association study of multiple sclerosis confirms a novel locus at 5p13.1. PLoS ONE 7: e36140.

Matsushita T, Madireddy L, Sprenger T, Khankhanian P, Magon S, Naegelin Y, Caverzasi E, Lindberg RL, Kappos L, Hauser SL, et al. 2015. Genetic associations with brain cortical thickness in multiple sclerosis. Genes Brain Behav 14: $217-227$

Maurano MT, Humbert R, Rynes E, Thurman RE, Haugen E, Wang H, Reynolds AP, Sandstrom R, Qu H, Brody J, et al 2012. Systematic localization of common disease-associated variation in regulatory DNA. Science 337: 1190-1195.
Mayes MD, Bossini-Castillo L, Gorlova O, Martin JE, Zhou X, Chen WV, Assassi S, Ying J, Tan FK, Arnett FC, et al. 2014. Immunochip analysis identifies multiple susceptibility loci for systemic sclerosis. Am J Hum Genet 94: 4761.

Minikel EV, MacArthur DG. 2016. Publicly available data provide evidence against $N R 1 H 3 \mathrm{R} 415 \mathrm{Q}$ causing multiple sclerosis. Neuron 92: 336-338.

Modin H, Masterman T, Thorlacius T, Stefansson M, Jonasdottir A, Stefansson K, Hillert J, Gulcher J. 2003. Genome-wide linkage screen of a consanguineous multiple sclerosis kinship. Mult Scler 9: 128-134.

Mokry LE, Ross S, Ahmad OS, Forgetta V, Smith GD, Goltzman D, Leong A, Greenwood CM, Thanassoulis G, Richards JB. 2015. Vitamin D and risk of multiple sclerosis: A Mendelian randomization study. PLoS Med 12: e1001866.

Monaghan F, Corcos A. 1984. On the origins of the Mendelian laws. J Hered 75: 67-69.

Moutsianas L, Jostins L, Beecham AH, Dilthey AT, Xifara DK, Ban M, Shah TS, Patsopoulos NA, Alfredsson L, Anderson CA, et al. 2015. Class II HLA interactions modulate genetic risk for multiple sclerosis. Nat Genet 47: 1107-1113.

Naito S, Namerow N, Mickey MR, Terasaki PI. 1972. Multiple sclerosis: Association with HL-A3. Tissue Antigens 2: $1-4$.

Nielsen NM, Frisch M, Rostgaard K, Wohlfahrt J, Hjalgrim H, Koch-Henriksen N, Melbye M, Westergaard T. 2008. Autoimmune diseases in patients with multiple sclerosis and their first-degree relatives: A nationwide cohort study in Denmark. Mult Scler 14: 823-829.

Nischwitz S, Cepok S, Kroner A, Wolf C, Knop M, MullerSarnowski F, Pfister H, Roeske D, Rieckmann P, Hemmer B, et al. 2010. Evidence for VAV2 and ZNF433 as susceptibility genes for multiple sclerosis. J Neuroimmunol 227: $162-166$.

O'Gorman C, Lin R, Stankovich J, Broadley SA. 2013. Modelling genetic susceptibility to multiple sclerosis with family data. Neuroepidemiology 40: 1-12.

Olerup O, Hillert J. 1991. HLA class II-associated genetic susceptibility in multiple sclerosis: A critical evaluation. Tissue Antigens 38: 1-15.

Pan G, Simpson S Jr, van der Mei I, Charlesworth JC, Lucas R, Ponsonby AL, Zhou Y, Wu F, Taylor BV. 2016. Role of genetic susceptibility variants in predicting clinical course in multiple sclerosis: A cohort study. J Neurol Neurosurg Psychiatry 87: 1204-1211.

Pandit L, Ban M, Sawcer S, Singhal B, Nair S, Radhakrishnan K, Shetty R, Misri Z, Hegde S, Bhat IG. 2011. Evaluation of the established non-MHC multiple sclerosis loci in an Indian population. Mult Scler 17: 139-143.

Parkes M, Cortes A, van Heel DA, Brown MA. 2013. Genetic insights into common pathways and complex relationships among immune-mediated diseases. Nat Rev Genet 14: 661-673.

Patsopoulos NA; International Multiple Sclerosis Genetics Consortium. 2016. 200 loci complete the genetic puzzle of multiple sclerosis. American Society of Human Genetics 2016 Annual Meeting, Abstract 4/6. Vancouver, Canada, October 18-22. 
Patsopoulos NA; Bayer Pharma MS Genetics Working Group; Steering Committees of Studies Evaluating IFN $\beta-1 b$, a CCR1-Antogonist, ANZgene Consortium; GeneMSA; International Multiple Sclerosis Genetics Consortium; Esposito F, Reischl J, Lehr S, et al. 2011. Genome-wide meta-analysis identifies novel multiple sclerosis susceptibility loci. Ann Neurol 70: 897-912.

Patsopoulos NA, Barcellos LF, Hintzen RQ, Schaefer C, van Duijn CM, Noble JA, Raj T, Imsgc, Anzgene, Gourraud PA, et al. 2013. Fine-mapping the genetic association of the major histocompatibility complex in multiple sclerosis: HLA and non-HLA effects. PLoS Genet 9: e1003926.

Pers TH, Karjalainen JM, Chan Y, Westra HJ, Wood AR, Yang J, Lui JC, Vedantam S, Gustafsson S, Esko T, et al. 2015. Biological interpretation of genome-wide association studies using predicted gene functions. Nat Commun 6: 5890 .

Raj T, Rothamel K, Mostafavi S, Ye C, Lee MN, Replogle JM, Feng T, Lee M, Asinovski N, Frohlich I, et al. 2014 Polarization of the effects of autoimmune and neurodegenerative risk alleles in leukocytes. Science 344: 519-523.

Ramagopalan SV, Dyment DA, Cader MZ, Morrison KM, Disanto G, Morahan JM, Berlanga-Taylor AJ, Handel A, De Luca GC, Sadovnick AD, et al. 2011. Rare variants in the CYP27B1 gene are associated with multiple sclerosis. Ann Neurol 70: 881-886.

Reich DE, Lander ES. 2001. On the allelic spectrum of human disease. Trends Genet 17: 502-510.

Rhead B, Baarnhielm M, Gianfrancesco M, Mok A, Shao X, Quach H, Shen L, Schaefer C, Link J, Gyllenberg A, et al. 2016. Mendelian randomization shows a causal effect of low vitamin D on multiple sclerosis risk. Neurol Genet 2: e97.

Ristori G, Cannoni S, Stazi MA, Vanacore N, Cotichini R, Alfo M, Pugliatti M, Sotgiu S, Solaro C, Bomprezzi R, et al. 2006. Multiple sclerosis in twins from continental Italy and Sardinia: A nationwide study. Ann Neurol 59: 27-34.

Roadmap Epigenomics Consortium; Kundaje A, Meuleman W, Ernst J, Bilenky M, Yen A, Heravi-Moussavi A, Kheradpour P, Zhang Z, Wang J, et al. 2015. Integrative analysis of 111 reference human epigenomes. Nature 518: 317-330.

Sadovnick AD, Dyment D, Ebers GC. 1997. Genetic epidemiology of multiple sclerosis. Epidemiol Rev 19: 99-106.

Sanna S, Pitzalis M, Zoledziewska M, Zara I, Sidore C, Murru $\mathrm{R}$, Whalen MB, Busonero F, Maschio A, Costa G, et al. 2010. Variants within the immunoregulatory $C B L B$ gene are associated with multiple sclerosis. Nat Genet 42: 495497.

Sawcer S, Franklin RJ, Ban M. 2014. Multiple sclerosis genetics. Lancet Neurol 13: 700-709.
Shiina T, Hosomichi K, Inoko H, Kulski JK. 2009. The HLA genomic loci map: Expression, interaction, diversity and disease. J Hum Genet 54: 15-39.

Slowikowski K, Hu X, Raychaudhuri S. 2014. SNPsea: An algorithm to identify cell types, tissues and pathways affected by risk loci. Bioinformatics 30: 2496-2497.

Smith GD, Ebrahim S. 2003. "Mendelian randomization": Can genetic epidemiology contribute to understanding environmental determinants of disease? Int J Epidemiol 32: $1-22$.

Stahl EA, Raychaudhuri S, Remmers EF, Xie G, Eyre S, Thomson BP, Li Y, Kurreeman FA, Zhernakova A, Hinks A, et al. 2010. Genome-wide association study meta-analysis identifies seven new rheumatoid arthritis risk loci. Nat Genet 42: 508-514.

Trynka G, Hunt KA, Bockett NA, Romanos J, Mistry V, Szperl A, Bakker SF, Bardella MT, Bhaw-Rosun L, Castillejo G, et al. 2011. Dense genotyping identifies and localizes multiple common and rare variant association signals in celiac disease. Nat Genet 43: 1193-1201.

Wagner GP, Zhang J. 2011. The pleiotropic structure of the genotype-phenotype map: The evolvability of complex organisms. Nat Rev Genet 12: 204-213.

Wang Z, Sadovnick AD, Traboulsee AL, Ross JP, Bernales CQ, Encarnacion M, Yee IM, de Lemos M, Greenwood T, Lee JD, et al. 2016. Nuclear receptor NR1H3 in familial multiple sclerosis. Neuron 90: 948-954.

Wellcome Trust Case Control Consortium; Australo-AngloAmerican Spondylitis Consortium; Burton PR, Clayton DG, Cardon LR, Craddock N, Deloukas P, Duncanson A, Kwiatkowski DP, McCarthy MI, et al. 2007. Association scan of 14,500 nonsynonymous SNPs in four diseases identifies autoimmunity variants. Nat Genet 39: 13291337.

Westerlind H, Kuja-Halkola R, Ramanujam R, Hillert J. 2014a. Reply: Shared environmental effects on multiple sclerosis susceptibility: Conflicting evidence from twin studies. Brain 137: e288.

Westerlind H, Ramanujam R, Uvehag D, Kuja-Halkola R, Boman M, Bottai M, Lichtenstein P, Hillert J. 2014b. Modest familial risks for multiple sclerosis: A registrybased study of the population of Sweden. Brain 137: 770-778.

Willer CJ, Dyment DA, Cherny S, Ramagopalan SV, Herrera BM, Morrison KM, Sadovnick AD, Risch NJ, Ebers GC. 2007. A genome-wide scan in forty large pedigrees with multiple sclerosis. J Hum Genet 52: 955-962.

Winchester R, Ebers G, Fu SM, Espinosa L, Zabriskie J, Kunkel HG. 1975. B-cell alloantigen Ag 7a in multiple sclerosis. Lancet 2: 814.

Wray NR, Goddard ME, Visscher PM. 2007. Prediction of individual genetic risk to disease from genome-wide association studies. Genome Res 17: 1520-1528. 


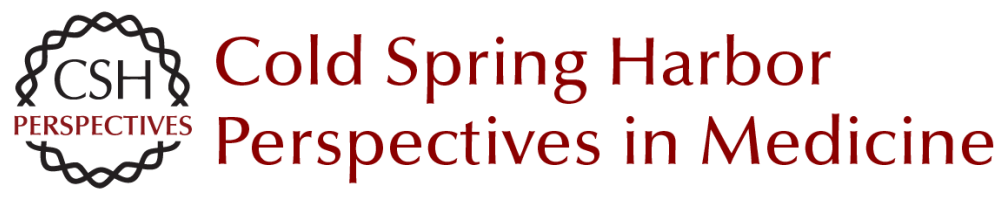

\section{Genetics of Multiple Sclerosis: An Overview and New Directions}

Nikolaos A. Patsopoulos

Cold Spring Harb Perspect Med 2018; doi: 10.1101/cshperspect.a028951 originally published online February 12, 2018

\section{Subject Collection Multiple Sclerosis}

Multiple Sclerosis Pathology Hans Lassmann

Regulatory T Cells: From Discovery to Autoimmunity Alexandra Kitz, Emily Singer and David Hafler

The Multiple Roles of B Cells in Multiple Sclerosis and Their Implications in Multiple Sclerosis Therapies Rui Li and Amit Bar-Or

Autologous Hematopoietic Stem Cell Transplantation in the Treatment of Multiple Sclerosis Carolina A. Rush, Harold L. Atkins and Mark S. Freedman

B-Cell Therapies in Multiple Sclerosis Joseph J. Sabatino, Jr., Scott S. Zamvil and Stephen L. Hauser

Oral Therapies for Multiple Sclerosis Simon Faissner and Ralf Gold

Interferon $\beta$ for Multiple Sclerosis Dejan Jakimovski, Channa Kolb, Murali Ramanathan, et al.

Alemtuzumab as Treatment for Multiple Sclerosis Serafeim Katsavos and Alasdair Coles

\author{
Natalizumab: Perspectives from the Bench to \\ Bedside \\ Afsaneh Shirani and Olaf Stüve \\ Daclizumab Therapy for Multiple Sclerosis \\ Bibiana Bielekova
}

Lifestyle and Environmental Factors in Multiple Sclerosis Lars Alfredsson and Tomas Olsson

Biomarkers in Multiple Sclerosis Anu Paul, Manuel Comabella and Roopali Gandhi

The Evolving Mechanisms of Action of Glatiramer Acetate Thomas Prod'homme and Scott S. Zamvil

Regulation of Astrocyte Functions in Multiple Sclerosis

Michael A. Wheeler and Francisco J. Quintana

Experimental Autoimmune Encephalomyelitis

(EAE) as Animal Models of Multiple Sclerosis (MS) Simon Glatigny and Estelle Bettelli

Neurodegeneration in Progressive Multiple Sclerosis Graham Campbell and Don Mahad

For additional articles in this collection, see http://perspectivesinmedicine.cshlp.org/cgi/collection/ 